I nt $r$ at hecal cocai ne del i very enabl es I ong- access sel $f$-admi ni st $r$ at $i$ on wi th bi nge- l i ke behavi or i $n$ mice

\begin{tabular}{|l|l|}
\hline 著者 & $\begin{array}{l}\text { Nakamur a Nasat o, Gao Shui bo, Okamur a Hi t oshi , } \\
\text { Nakahar a Dai i chi ro }\end{array}$ \\
\hline $\begin{array}{l}\text { j our nal or } \\
\text { publ i cat i on t i tl e }\end{array}$ & Psychophar nacol ogy \\
\hline vol une & 213 \\
\hline number & 1 \\
\hline page r ange & $119-129$ \\
\hline year & $2011-01$ \\
\hline URL & ht t p: //hdl . handl e. net /10271/2675 \\
\hline
\end{tabular}




\title{
Intrathecal cocaine delivery enables long-access self-administration with binge-like behavior in mice
}

\author{
Masato Nakamura ${ }^{1,2}$, Shuibo Gao ${ }^{1}$, Hitoshi Okamura ${ }^{3}$ and Daiichiro Nakahara ${ }^{1}$ \\ ${ }^{1}$ Department of Psychology and Behavioral Neuroscience, Hamamatsu University \\ School of Medicine, Hamamatsu, Japan, ${ }^{2}$ Fuji Rehabilitation Institute, Fuji, Japan, \\ ${ }^{3}$ Department of System Biology, Kyoto University Graduate School of Pharmaceutical \\ Science, Kyoto, Japan
}

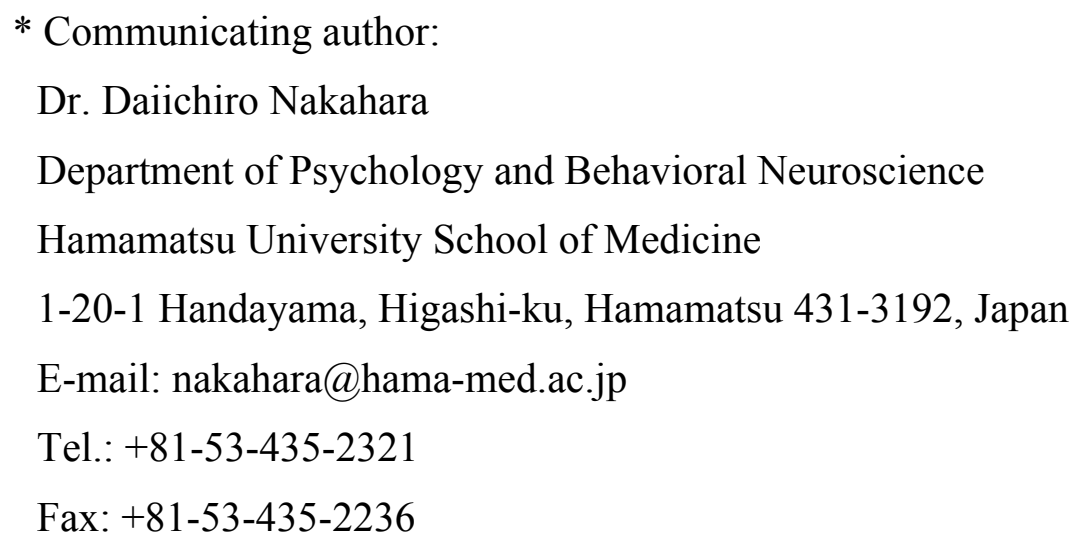

\section{Acknowledgments}

We are grateful to M. Ogawa and Y. Yasuhiro (The Laboratory of Patho-Physiological Imaging, Functional Imaging, Photon Medical Research Center, Hamamatsu University School of Medicine) for acquiring the CT image. We thank S. Sugiyama and M. Edamura for preparing the artwork. This study was supported in part by Grants-in-Aid for Scientific Research (B) 14310039 and 17330153, the Ministry of Education, Culture, Sports, Science, and Technology (MEXT), and for Scientific Research from The $21^{\text {st }}$ Century Center of Excellence Program from the MEXT of Japan, and by a Smoking Research Foundation Grant for Biochemical Research (Japan).

\section{Competing Interest Statement}

The authors declare no competing financial interests. 


\begin{abstract}
Rationale: Long-access intravenous drug self-administration shows diurnal alterations in drug intake, with escalation and binge patterns, in rats. A similar long-access model in mice would allow the use of genetically modified animals to better understand the molecular mechanisms underlying drug addiction and relapse. However, attempts to transfer this model to mice have been less successful, mainly because of technical difficulties with long-term maintenance of the indwelling catheter implanted into small veins.
\end{abstract}

Objectives: We devised an intrathecal probe implanted in the supracerebellar cistern as an alternative for intravenous drug administration to address this challenge and allow continuous, chronic drug self-administration in mice.

Results: We found that mice readily self-administered intrathecal infusions of cocaine as a drug reward, and, under daily $24-\mathrm{h}$ access conditions, animals exhibited a binge-like behavior comparable to rats.

Conclusions: This innovation enables a full analysis of long-access drug self-administration behavior in mice not possible with intravenous administration.

\title{
Key words
}

addiction, diurnal rhythm, cocaine, locomotion, mice, microdialysis, relapse, self-administration

\section{Abbreviations}

ANOVA: analysis of variance; CSF: cerebrospinal fluid ; CT: computed tomography; FR: Fixed ratio 


\section{Introduction}

Cocaine is a psychoactive drug that is highly addictive and readily self-administered by animals such as mice, rats and monkeys. The addictive aspect of the drug has been so far studied mainly using rat models of intravenous self-administration in which differential drug accessibility produces different patterns of consumption. Typically, short access to cocaine a few hours per day (generally, less than $3 \mathrm{~h}$ ) produced the stable and regular pattern of drug intake, while increasing drug access time (e.g., 6 h) invoked escalated intake (Ahmed and Koob 1998, 1999; Ahmed et al. 2003). Furthermore, rats given continuous $24 \mathrm{~h}$ access to the drug developed all the major behavioral symptoms of addiction including a binge-like pattern of cocaine seen in human addicts (Bozarth and Wise 1985). Thus, long-access regimens allow for inducing and evaluating more addiction-like behaviors in rats than does a short-access regimen. However, a mouse model of long-access drug self-administration has not been successfully established (except for Olsen and Winder 2009), largely because of technical difficulties in placing the indwelling catheter into a small jugular or other vein and long-term maintenance without occlusion. (Chistyakov and Tsibulsky 2006; Epstein et al. 2006; Grahame et al. 1995; Olsen and Winder 2006; Thomsen and Caine, 2007). Consequently, previous mouse studies using intravenous self-administration have been conducted exclusively with short access to cocaine one to three hours per day (Fuchs et al. 2003; Grahame et al. 1995; Highfield et al. 2002; Soria et al. 2005, 2008; Yan et al. 2006, 2007; Zhang et al. 2006). Clearly, these short-access regimens are not effective for measuring addiction-like behavior in wild-type mice as well as gene knockout or transgenic mice, which are particularly attractive animals to evaluate the role of specific genes in drug addiction. Therefore, the development of a reliable long-access self-administration regimen for use in the mouse is highly desirable.

We have used an intrathecal microdialysis probe permanently implanted into cerebrospinal fluid (CSF) of the supracerebellar cistern to establish continuous and chronic monitoring of melatonin (Nakahara et al. 2003) and corticosterone (Ishida et al. 2005) levels of the same mouse. The success of long-term monitoring was predominantly attributable to minimal tissue reactions in the CSF to form a diffusion barrier on the dialysis membrane. Microdialysis can collect endogenous compounds as well as administer drugs. Moreover, with drug administration through the dialysis membrane, no volume is added to the CSF, which in principle enables animals to gain 
unlimited access to the drug with no volume expansion. Rats reliably self-administer drugs into the CSF via intraventricular (Amit et al. 1976; De Vry et al. 1989) or intrathecal (Martin et al. 2006) catheters, indicating that intrathecal delivery by reverse dialysis may permit long access to drugs of addiction in mice.

We used this technique to examine the diurnal pattern of cocaine self-administration in normal mice under daily 24 -h access conditions. The objective was to develop and validate a long-access model of drug self-administration in mice analogous to that in rats (Fitch and Roberts 1993; Roberts et al. 2002).

\section{Methods}

Subjects.

All procedures were approved by the Hamamatsu University School of Medicine Animal Care and Use Committee, and were carried out with the National Institute of Health Guide for the Care and Use of Laboratory animals (NIH Publications No. 80-23). All efforts were made to minimize animal suffering and reduce the number of animals used. Male C57BL/6 mice (Japan SLC Inc., Shizuoka, Japan), one of the most common parental strains of genetically engineered mice, weighing 24-32 g at the time of surgery, were used. The animals were individually housed under a 12 light (L): 12 dark (D) schedules (lights on 07:00, lights off 19:00) in a temperature-controlled environment $\left(23-25^{\circ} \mathrm{C}\right)$ for at least one week before the experiment, with food and water available ad libitum.

\section{Drugs.}

Cocaine hydrochloride (Dai-Nihon, Osaka, Japan) was dissolved in Ringer solution (138 mM NaCl, $2.4 \mathrm{mM} \mathrm{KCl}, 1.2 \mathrm{mM} \mathrm{CaCl}_{2}$, at $\left.\mathrm{pH} 7.0\right)$ and filter-sterilized before use. All doses are expressed as the weight of the salt.

\section{Probe Surgery.}

The experiments were performed with a modified transverse probe as described elsewhere (Nakahara et al. 2003). The probe contains the following two components (Fig. 1): a tubular dialysis membrane $(0.24 \mathrm{~mm}$ o.d.; $0.01 \mathrm{~mm}$ wall width; 5,000 MW cut-off; Cuprophan hollow fiber, Eicom, Kyoto, Japan) and teflon tubes (0.4 mm o.d.; $0.02 \mathrm{~mm}$ wall width, $20 \mathrm{~mm}$ long; TN-28, Unique Medical, Tokyo, Japan). 
The surface of the dialysis membrane with a length of $20 \mathrm{~mm}$ is glued with an epoxy resin (Araldite Rapid; CIBA-GEIGY) except for a center zone, $2 \mathrm{~mm}$ wide. The teflon tube is bent in approximately an $90^{\circ}$ angle with the base, $3 \mathrm{~mm}$ long. The animals were anesthetized with sodium pentobarbital $(50 \mathrm{mg} / \mathrm{kg}$, i.p.) and placed in a Narishige apparatus with skull level between bregma and lambda. One hole was made on each side of the skull $(0.0 \mathrm{~mm}$ anterior and $0.4 \mathrm{~mm}$ ventral to lambda) with a dental drill and a dialysis tube was transversely inserted in the supracerebellar cistern, under the guidance of a stainless wire attached in a horizontal position to a stereotaxic holder. The transverse probe was kept in place by dental cement and then tubing was cut to a length of $3 \mathrm{~mm}$ extending beyond the cement. The bent teflon tubes, one for the inlet and the other for the outlet, were then passed over the membrane tubing and glued in an upright position with the resin. Next, the probe was fixed to the skull with dental cement and surgical adhesive (Daiichi Sankyo Co. Ltd., Tokyo, Japan), and a small plastic chamber was cemented to the animal's head to protect the probe. Finally, a plastic hook was embedded inside the chamber to connect a tether line. The mice were individually housed in the colony room and allowed to recover from the surgery for 7-10 days, during which the probe was flushed once every 3 days with the Ringer to maintain its patency.

\section{Determination of cocaine doses infused through the probe.}

The in vitro diffusion rate of cocaine through the probe was determined as follows. The probe was immersed into a microtube filled with the Ringer solution, and the probe was perfused at a constant flow rate. The perfusate was identical to the solution outside the probe except that it contained cocaine $(100 \mathrm{mg} / \mathrm{ml})$. The concentration of cocaine in the perfusate and the dialysate was quantified by high-performance liquid chromatography with ultraviolet detection. From the values obtained, the in vitro diffusion rate was calculated by the following formula:

In vitro diffusion rate $(\%)=100-($ cocaine concentration in the dialysate $) /($ cocaine concentration in the perfusate) $\mathrm{x} 100$

The in vitro diffusion rate of cocaine with our probes was $2.03 \pm 0.15 \%$ (mean $\pm \mathrm{SEM}$, $\mathrm{n}=10)$ at a rate of $12 \mu \mathrm{l} / \mathrm{min}$ at $37^{\circ} \mathrm{C}$. Based on this estimate and the concentration (100 $\mathrm{mg} / \mathrm{ml}$ ) of the cocaine solution used, the cocaine from each infusion of the $7.5,15,30$, 60 or $120 \mathrm{sec}$ duration would approximate to $3,6,12,24$, or $48 \mu \mathrm{g} /$ infusion, 
respectively, in the CSF of the supracerebellar cistern. These doses of cocaine were chosen based on a study indicating that rats trained with intraventricular 25-100 $\mu \mathrm{g} /$ infusion (approximately $0.25-10 \mu \mathrm{g} /$ infusion assuming a $30 \mathrm{~g}$ mouse) displayed rapid and reliable acquisition of self-administration behavior (Guzman and Ettenberg 2007).

\section{Self-administration chambers}

The chambers $(30 \times 30 \times 35-\mathrm{cm})$ are designed as permanent housing for studies that require daily $24-\mathrm{h}$ access to drug self-administration. They contained two nose-poke holes (one is the active hole for delivering the reinforcer and the other is inactive) and a light and buzzer located above the active hole (Fig. 2). Mice normally have free access to food and water. Daytime illumination measured at the level of the floor was 150 to 220 lux. During the night, there was a continuous dim red light of $<1$ lux. After recovery from surgery, animals were moved to self-administration chambers, and connected to the drug-delivery system with a dual liquid swivel (Instech, model 375/D/22QM, Plymouth Meeting, PA) by putting the tether line on the hook on the animal's head. One side of the swivel was connected to two syringes mounted in two one-channel infusion pumps (Univentor, Zejtun, Malta; one is used for administration of the Ringer solution and the other for drug administration) with PE-10 polyethylene tubing. The other side of the swivel was connected to the inlet port of the transverse probe on the animal's head through a three way joint with polyethylene tubing. The tubing was then fixed firmly to the tether line and suspended into the self-administration chamber from the swivel mounted on a counter-balanced arm. The outlet port of the probe was connected, through PE-10 tubing, to a sample vial. Throughout the experiment, the probe was continuously perfused with the Ringer solution at a flow rate of $1 \mu \mathrm{l} / \mathrm{min}$. Probe patency was checked by measuring the amount of Ringer and/or drug solutions collected in the sample tube each day, and was maintained by delivering a brief pulse of the Ringer once daily from the infusion pump to prevent tissue clogging. Animals with leaky or clogged probes during the course of the experiment were excluded from the experiment and data analysis. The chambers were also equipped with an infrared sensor (Muromachi-kikai, Tokyo, Japan) placed on the ceiling to measure locomotor activity. Experimental procedures were run and behavioral data collected through a personal computer (Nippon System Technology, Hamamatsu, Japan). 
Experiment 1: Cocaine self-administration procedure, drug-dependent effect, and priming-induced reinstatement under 24-h access schedules

Cocaine self-administration sessions were conducted without any initial priming using the schedule described below. Responses were maintained by $12 \mu \mathrm{g}$ of cocaine infused through the dialysis membrane. Mice were allowed to nose-poke in the active hole to receive a cocaine infusion under a Fixed ratio (FR) 1 schedule of reinforcement. Active nose-poking produced a brief feedback tone and hole-light. Following each cocaine infusion, the cue light above the hole signaled the delivery of the reinforcer and remained on for a $60-\mathrm{sec}$ time-out period, during which responses were counted but not reinforced. Nose-poking in the inactive hole was also recorded but had no scheduled consequence. After mice achieved the acquisition criteria (at least 10 reinforcers per day, a minimum of $70 \%$ responding on the active hole, and less than $20 \%$ variability in number of reinforced responses for 3 consecutive days), a cocaine dose-response curve was determined using a descending order. The animals received five doses of cocaine $(3,6,12,24$ and $48 \mu \mathrm{g})$, and were given three sessions at each dose. Following completion of the dose-response curve, all the mice were given 10 extinction sessions. The conditions at extinction were the same as during the training phase, except that nose-poke responses in the active hole resulted in a delivery of the Ringer rather than cocaine. The Ringer infusions were accompanied by the presentation of the compound cue that was previously paired with cocaine infusions. Following the last extinction day, the effect of priming infusion of cocaine (48 $\mu \mathrm{g} / \mathrm{infusion})$ on the reinstatement of cocaine seeking was examined. The priming infusion was performed $30 \mathrm{~min}$ before the onset of the dark/active phase. The conditions during the reinstatement phase were the same as during the extinction phase.

Experiment 2: Diurnal patterns of cocaine self-administration under 24-h access schedules and cue-induced cocaine seeking

Mice in a separate group received surgery, recovered, and then assigned randomly to cocaine and vehicle control groups. Mice in the cocaine group were allowed to self-administer the drug at a dose of $12 \mu \mathrm{g} /$ infusion because the binge pattern of intake appears more likely when animals are given high doses of cocaine (Fitch and Roberts 1993; Roberts et al. 2002). Daily 24 h sessions were conducted for 20 days, 
with unlimited access to cocaine. During training, cocaine was made available on an FR1 schedule for 10 days and then on an FR2 schedule for a further 10 days. Thereafter, mice underwent 7 consecutive days of withdrawal trials, during which the holes were covered with tape in order for mice to have no access to cocaine. On the day after the last withdrawal day, the effect of the compound cue on cocaine seeking was examined in a response-contingent manner. The conditions at this test were the same as the training phase, with the exception that nose-poke responses in the active hole did not result in cocaine infusions.

Mice in the vehicle control group were treated exactly as the cocaine group except that they received the Ringer solution via the intrathecal probes instead of cocaine.

\section{Computed Tomography imaging}

After the self-administration tests described above, four animals from the cocaine group in experiment 2 received computed tomography (CT) scans to evaluate the location of the probe. Each animal was anesthetized with pentobarbital and placed in a prone position. Then, contrast material (Iopamiron 150, Bayer Japan Co., Tokyo, Japan) was injected into the probe using a 27 gauge standard needle connected to a syringe. CT of the brain was performed to observe the placement of the membrane. The images were obtained by a small-animal PET (small animal PET/SPECT/CT system, FLEX, GMI, USA) and reconstructed using FLEX Triumph ${ }^{\mathrm{TM}}$ Platform (FLEX TM $\mathrm{X}$-PET Image Reconstruction).

\section{Statistical analysis}

Data are presented as the mean $( \pm$ SEM) number of cocaine infusions, nose-pokes, and locomotor activity counts. The nose-poke data from the self-administration or from the extinction were analyzed by two-way analysis of variance $($ ANOVA) $($ Day $\times$ Hole) with repeated measures, followed by one-way repeated ANOVAs for differences between the active and the inactive holes or for differences between first and last three days. The data for the dose response curves and intake were analyzed using one-way repeated ANOVAs followed by Bonferroni post hoc tests. Wilcoxon sign-ranked tests were used to analyze the effects of cocaine priming on reinstatement and associated locomotor activity. A paired $t$ test was used to 
analyze the effect of FR contingency on nose-poke responses. The effect of cue presentation on cocaine seeking was analyzed by using two-way ANOVA (Group x Hole) with repeated measures, followed by one-way repeated ANOVAs for comparisons between holes or between groups. Associated locomotor activity was analyzed by using a paired $t$ test. The correlation between nose-poke responding and associated locomotor activity was analyzed by using Spearman's rank correlation coefficient.

\section{Results}

Dose-response effect and priming-induced reinstatement

We implanted the intrathecal probe in a total of 10 mice. We first examined whether mice can learn to nose-poke to receive an intrathecal infusion of cocaine delivered through the dialysis membrane, as well as optimal dosing in the CSF. Mice were allowed to self-administer cocaine at an initial dose of $12 \mu \mathrm{g}$ per infusion in an FR1 schedule under 24-h access conditions. Seven of 10 animals examined met the training criteria in a mean \pm SEM of $7.7 \pm 1.1$ days. These mice discriminated between the active and inactive holes and self-administered cocaine $(F(1,6)=43.64, p=0.0006$; Fig. 3), as observed in intravenous self-administration (Soria et al. 2005, 2008). The remaining three mice were excluded from further analysis due to loss of probe patency during the training phase $(n=2)$ or failure to acquire cocaine self-administration $(n=1$, $<70 \%$ responding on the active hole). Seven mice that met acquisition criteria were subsequently tested with descending infusion doses of cocaine, with each dose available for 3 test days, and five of these mice exhibited an inverted U-shaped dose-response curve (Fig. 4a,b), with a maximal peak at $6 \mu \mathrm{g} /$ infusion. Two mice were excluded due to probe failure before completion of the full within-subjects dose-dependent effects. When dose-response data were transformed into dose-intake data based on the total amount of cocaine consumed in the 3-day sessions, the overall intake was directly related to unit dose (Fig. 4c). Locomotor activity also demonstrated an inverted U-shaped dose-related effect, but with a maximal peak at a higher dose (Fig. 4d). The different dose profiles of nose-poking and locomotor activity indicate a difference in susceptibility to cocaine between the reinforcing and the psychomotor effects. The subsequent 10 days of extinction training resulted in a gradual decrease in active nose-poke responses $(F(9,36)=2.51, p=0.024)$ (Fig. 5a). There were differences in 
extinction responding between holes $(F(1,4)=13.41, p=0.021)$ or interaction between hole and day $(F(9,36)=3.09, p=0.008)$. On the last three days, the average number of active nose-poke responses was significantly low as compared with that on the first three days of extinction phase $(t=-4,38, d f=4, p=0.012)$. However, it is noteworthy that a relatively high number of responding was seen even after extensive extinction. This seems to correspond to the idea that conditioned cues or nose-poking in mice are reinforcing in themselves (Spanagel and Sanchis-Segura, 2003). Thereafter, mice were exposed to an intrathecal, rather than intraperitoneal, priming injection of 48 $\mu \mathrm{g} /$ infusion cocaine $30 \mathrm{~min}$ prior to the start of the test sessions. When the last day of extinction served as the no-drug (the Ringer only) baseline condition, priming infusions increased responses on the previously extinguished active hole $(\mathrm{T}=7.5, \mathrm{n}=5, p=0.0313$, one-tailed) (Fig. 5b), but had no effect on responding on the inactive hole. Priming cocaine infusions also increased locomotor activity levels beyond the baseline $(\mathrm{T}=7.5$, $\mathrm{n}=5, p=0.0313$ ) (Fig. 5c). However, there was no correlation between the total number of nose-pokes and activity counts (Spearman's coefficient $=0.21, p=0.7833$ ), ruling out the possibility that a priming-induced increase in nose-poke responses was simply an increase in associated locomotor activity.

\section{Diurnal pattern of self-administration and cue-induced cocaine seeking}

We implanted the intrathecal probe in a total of 16 mice $(n=10$ in the cocaine group; $n=6$ in the control group). As the intrathecal infusion worked as a route of cocaine self-administration, we next examined whether continuous access to cocaine produced a diurnal pattern of self-administration. For this purpose, mice were allowed to self-administer cocaine (or the Ringer) at $12 \mu \mathrm{g}$ per infusion on an FR1 schedule for 10 days and then on an FR2 schedule for a further 10 days under daily 24-h access conditions. Five of the implanted animals in the cocaine group were excluded from statistical analysis due to failure to acquire cocaine self-administration ( $n=3$, nose-poke ratio of FR2 to $\mathrm{FR} 1 \approx 1$ ), or health deterioration during acquisition of cocaine self-administration $(n=2)$. No mice in the control group were excluded based on the self-administration criteria. Animals in the cocaine $(F(1,4)=25.50, p=0.0072)$, but not the control $(F(1,5)=0.47, p=0.5249)$, group gradually discriminated between the active and inactive holes (Fig. 6 a, b). Furthermore, the number of nose-pokes in the active hole increased substantially in the cocaine group when the FR was doubled from FR1 to 
FR2 ( $t=4.07, d f=4, p=0.0152)$ (Fig. 6c), confirming the motivation to self-administer cocaine, comparable with that observed with intravenous methamphetamine (Yan et al. 2006), while nose-pokes remained at low levels in the control group. The cocaine group showed drug intake primarily in the dark phase of the light/dark cycle (Fig. 7b), indicating a clear diurnal pattern of cocaine intake. However, 3 of 7 mice increased their drug intake beyond the dark phase into the light phase (Fig. 7c). As sessions advanced, the pattern of cocaine self-administration became disrupted and less related to the day/night cycle. In one mouse (M300), the initial binge-like behavior, characterized by extended episodes of high cocaine intake and activity, appeared with a period of almost $40 \mathrm{~h}$, and the second and third binges lasted for $44 \mathrm{~h}$ and $38 \mathrm{~h}$, respectively. In the other mouse (M297), the binge-like behavior appeared once for $67 \mathrm{~h}$. Of the three mice that displayed this typical binge-like pattern of cocaine self-administration, two died from weight loss during a session characterized by high cocaine intake. Thus, we demonstrated in mice for the first time that continuous access to cocaine can cause a binge-like pattern of self-administration, comparable to those observed in rats (Bozarth and Wise 1985) and monkeys (Johanson et al. 1976). Then, we tested for cue-induced cocaine seeking after withdrawal in the remaining five animals. The compound cue, when presented again after a 7-day withdrawal period, vigorously evoked drug-seeking behavior. As compared with responding in mice of the control group, the cue significantly increased overall responses on the previously active and inactive holes in mice of the cocaine group $(F(1,9)=13.11, p=0.006)$, with a more pronounced effect on the active hole $(F(1,9)=19.79, p=0.002)$ (Fig 8a). However, there was no difference in locomotor activity levels between control and cocaine groups $(t=1.03, d f=9, \mathrm{~ns})$ (Fig. 8b). Thus, it is unlikely that the increase in locomotion contributed to the difference in nose-poke responses between groups.

\section{Discussion}

Normal C57BL/6 mice easily learn to nose-poke to receive intrathecal infusions of cocaine through a microdialysis membrane. We also found, for the first time, a clear daily rhythm of cocaine self-administration in mice, with a greater intake during the active or dark period than the inactive or light period.

Characteristics of long-access self-administration in mice by intrathecal cocaine 
delivery

Under 24-h access, 3 of 7 mice developed binge-like cocaine self-administration, in line with findings in rats (Bozarth and Wise 1985). Cocaine self-administration in mice followed a diurnal periodicity, with a larger intake during the night than the day. However, cocaine intake is progressively increased and the diurnal pattern of intake is virtually lost when animals are given access to more trials. This drug escalation and disturbance of diurnal patterns is reminiscent of a core feature of drug use seen in rats (Fitch and Roberts 1993; Roberts et al. 2002). A proper evaluation of addictive behavior requires additional testing, i.e., the reinstatement procedure, which is conducted to study relapse of drug use following training for drug self-administration and subsequent prolonged periods of abstinence. In this procedure, the ability to reinstate a previously extinguished drug-reinforced behavior is assessed in response to non-contingent drug delivery (i.e. priming) and/or environmental cues previously associated with it. Here, there was an increase in drug seeking behavior when mice were intrathecally given priming injections of cocaine after extinction periods, as previously shown in a reinstatement model in mice with a history of intravenous cocaine self-administration (Highfield et al. 2002; Olsen and Winder 2006; Soria et al. 2008), and consistent with the idea that cocaine-induced reinstatement requires the same route of administration during training and testing in C57BL/6 (Fuchs et al. 2003) and other strains (Highfield et al. 2002). A test for cue-induced drug seeking conducted separately showed a large increase in cocaine seeking behavior when mice were re-exposed to a compound cue previously paired with the drug following withdrawal periods. The result is comparable to previous reports using intravenous drug self-administration in mice (Fuchs et al. 2003; Highfield et al. 2002; Soria et al. 2008) demonstrating that stimuli previously paired with drug infusions during training would provoke drug seeking when they are re-introduced in the absence of the drug following extinction periods. Thus, mice undergoing this procedure developed behavioral changes that resemble some of the core features of drug craving and relapse in rats.

\section{Future perspective}

Studies of drug addiction have moved toward the use of genetically engineered models in which key genes are knocked out or overexpressed. Using a 24-h access paradigm, 139 genes were significantly up- or down-regulated in the rat striatum 
following 7 days of cocaine self-administration, 29 of which were associated with the circadian signaling (Lynch et al. 2008), suggesting the involvement of circadian-associated genes in the addictive process. Interestingly, the direct manipulation of circadian genes, including Clock and $m P e r$, alters vulnerability to drugs of abuse (Abarca et al. 2002; McClung et al. 2005; Spanagel et al. 2005). For example, mPer2 knockouts show enhanced behavioral sensitization to repeated cocaine administration and increased cocaine-induced place preference, whereas knockout of mPerl produced neither sensitization nor place preference (Abarca et al. 2002). Also, mPer2 knockout mice displayed a higher rate of ethanol consumption (Spanagel et al. 2005). Furthermore, Clock/Clock mutants exhibited robust behavioral sensitization to repeated cocaine as well as cocaine-induced place preference (McClung et al. 2005). However, these studies of mice with altered circadian genes have focused on behavioral manifestations of drug response at specific time points across the day. No studies have analyzed genetic influences on the diurnal patterns of drug response in these or self-administration models. Here, we have demonstrated an intrathecal probe method for the long-term measurement of drug self-administration together with locomotor activity in mice. This innovation enables us to assess multiple time points for self-administration behavior across a whole day or over days to months.

\section{Methodological considerations}

A detailed description of the surgical and behavioral procedures is included because there are few reports of measurements for chronic drug self-administration in mice. The method is a modification of one developed in our laboratory for use in long-term microdialysis of CSF melatonin (Nakahara et al. 2003) or corticosterone (Ishida et al. 2005) in mice. The cisterna magna and supracerebellar cistern are two of the largest non-ventricular CSF spaces. The supracerebellar cistern was used here because of the relative ease of surgery. Following cisterna magna injection, $\left[{ }^{14} \mathrm{C}\right]$ insulin, a marker of CSF bulk flow, distributes in all directions through the subarachnoid spaces and penetrates into the brain parenchyma at basal cisterns, which includes the ventral forebrain and brainstem (Proescholdt et al. 2000). There appears to be little difference in tracer entry and parenchymal distribution after cisterna magna versus supracerebellar cistern injections. Thus, cocaine may spread in all directions within the subarachnoid spaces and enter the brain to interact with dopamine transporters to produce rewarding 
and psychomotor effects. Preliminarily, we used 6 mice with the probe implanted in the supracerebellar cistern to measure the delay between intrathecal cocaine infusion and locomotion. When a $12 \mu \mathrm{g}$ unit dose of cocaine was administered through the probe over a period of $30 \mathrm{sec}$, we observed that animals began to move within 80-140 seconds after termination of the drug administration. The average delay between the termination of cocaine infusion and the subsequent onset of locomotion was $108 \pm 9 \sec (n=6)$. In spite of this slow effect of cocaine on locomotion, mice reliably learned to self-administer the drug delivered at the same dose and the same infusion rate. In general, responding for cocaine correlates positively with the speed with which the drug is delivered. That is, faster infusions (10 sec infusion duration) of cocaine are more reinforcing than slower infusions $(100 \mathrm{sec})$ during acquisition but not maintenance of drug self-administration in rats (Schindler et al, 2009). Nonetheless, over the range of doses that support self-administration, cocaine taking is less affected by infusion rate ( 5 , 25, 50 and $100 \mathrm{sec}$ infusion duration) in rats (Crombag et al, 2008). Consistent with the latter notion, cocaine doses used in the current study in mice would be reinforcing beyond the effect of infusion speed.

Two factors helped maintain long-term probe patency: continuous Ringer perfusion and the location of the probe in the CSF of the supracerebellar cistern, a region relatively free from diffusion barriers. Microdialysis is frequently used in combination with self-administration experiments to measure neurochemical changes in specific brain regions such as nucleus accumbens (Ahmed et al. 2003; Ikegami et al. 2007; Kippin et al. 2008; McFarland et al. 2003) or medial prefrontal cortex (Ikegami et al. 2007; Kippin et al. 2008). Nevertheless, long-term collection of dialysate samples has proved difficult, probably owing to rapid formation of diffusion barriers on the membrane in the parenchyma of the brain. Interestingly, preliminary experiments using our intrathecal probe indicate that it is possible to measure repeatedly amino acids and monoamine metabolites when mice engage in chronic drug self-administration (S. Gao, M. Nakamura, H. Okamura and D. Nakahara, unpublished observations). A similar approach has been successfully used by other investigators to collect samples in CSF of the rat spinal cord (Gerin et al 1994; Marsala et al. 1995) or in the vitreous fluid of rabbit eyes (Waga and Ehinger 1995; Zhang et al. 2001) over an extended period. Thus, an additional advantage of the intrathecal probe is the ability to collect CSF samples during chronic drug administration. The drawback of this method is low efficiency of 
drug diffusion into the CSF. As the membrane serves as a filter, only a small amount of drug in the perfusate enters into the CSF. Therefore, especially when the drug is expensive, the traditional catheterization of ventricles or veins has better cost performance than the microdialysis method. Furthermore, continuous perfusion of the probe by Ringer solution is cumbersome. At the flow rate of $1 \mu 1 / \mathrm{min}$, the syringe must be filled to $5 \mathrm{ml}$ with Ringer solution every three days. It should be also noted that the final attrition rate of the intrathecal self-administration procedure was about $50 \%$ but no better than the rate of attrition of the intravenous self-administration method (see Olsen and Winder 2006). Thus, although further improvement is required to validate this intrathecal probe method fully, it provides an adequate and powerful alternative to traditional intravenous catheters for continuous, chronic drug self-administration in mice. 


\section{References}

Abarca C, Albrecht U, Spanagel R (2002) Cocaine sensitization and reward are under the influence of circadian genes and rhythm. Proc Natl Acad Sci USA 99:9026-9030.

Ahmed SH, Koob GF (1998) Transition from moderate to excessive drug intake: change in hedonic ser point. Science 282:298-300.

Ahmed SH, Koob GF (1999) Long-lasting increase in the set point for cocaine self-administration after escalation in rats. Psychopharmacology 146:303-312.

Ahmed SH, Lin D, Koob GF, Parsons LH (2003) Escalation of cocaine self-administration does not depend on altered cocaine-induced nucleus accumbens dopamine levels. J Neurochem 86:102-113.

Amit Z, Brown ZW, Sklar LS (1976) Intraventricular self-administration of morphine in naive laboratory rats. Psychopharmacology (Berl) 48:291-294.

Bozarth MA, Wise RA (1985) Toxicity associated with long-term intravenous heroin and cocaine self-administration in the rat. JAMA 254:81-83.

Chistyakov VS, Tsibulsky VL (2006) How to achieve chronic intravenous drug self-administration in mice. J Pharmacol Toxicol Methods 53:117-127.

Crombag HS, Ferrario CR, Robinson TE (2008) The rate of intravenous cocaine or amphetamine delivery does not influence drug-taking and drug-seeking behavior in rats. Pharmacol Biochem Behav 90:797-804.

De Vry J, Donselaar I, Van Ree JM (1989) Intraventricular self-administration of heroin in the rat: reward seems dissociated from analgesia and physical dependence. Eur J Pharmacol 161:19-25.

Epstein DH, Preston KL, Stewart J, Shaham Y (2006) Toward a model of drug relapse: an assessment of the validity of the reinstatement procedure. Psychopharmacology (Berl) 189:1-16.

Fitch TE, Roberts DC (1993) The effects of dose and access restrictions on the periodicity of cocaine self-administration in the rat. Drug Alcohol Depend 33:119-128.

Fuchs RA, See RE, Middaugh LD (2003) Conditioned stimulus-induced reinstatement of extinguished cocaine seeking in C57BL/6 mice: a mouse model of drug relapse. Brain Res 973: 99-106.

Grahame NJ, Phillips TJ, Burkhart-Kasch S, Cunningham CL (1995) Intravenous cocaine self-administration in the C57BL/6J mouse. Pharmacol Biochem Behav 51:827-834.

Gerin C, Legrand A, Privat A (1994) Study of 5-HT release with a chronically implanted microdialysis probe in the ventral horn of the spinal cord of unrestrained rats during exercise on a treadmill. $\mathrm{J}$ Neurosci Methods 52:129-141.

Guzman D, Ettenberg A (2007) Runway self-administration of intracerebroventricular cocaine: evidence of mixed positive and negative drug actions. Behav Pharmacol 18:53-60.

Highfield DA, Mead AN, Grimm JW, Rocha BA, Shaham Y (2002) Reinstatement of cocaine seeking in 129X1/SvJ mice: effects of cocaine priming cocaine cues and food deprivation. Psychopharmacology (Berl) 161:417-424. 
Ishida A, Mutoh T, Ueyama T, Bando H, Masubuchi S, Nakahara D, Tsujimoto G, Okamura H (2005) Light activates the adrenal gland: timing of gene expression and glucocorticoid release. Cell Metab 2:297-307.

Ikegami A, Olsen CM, D'Souza MS, Duvauchelle CL (2007) Experience-dependent effects of cocaine self-administration/conditioning on prefrontal and accumbens dopamine responses. Behav Neurosci 121:389-400.

Johanson CE, Balster RL, Bonese K (1976) Self-administration of psychomotor stimulant drugs: the effects of unlimited access Pharmacol Biochem Behav 4:45-51

Kippin TE, Szumlinski KK, Kapasova Z, Rezner B, See RE (2008) Prenatal stress enhances responsiveness to cocaine. Neuropsychopharmacology 33:769-782.

Lynch W.J, Girgenti M.J, Breslin F.J, Newton SS, Taylor JR (2008) Gene profiling the response to repeated cocaine self-administration in dorsal striatum: A focus on circadian genes. Brain Res 1213:166-177.

Marsala M, Malmberg AB, Yaksh TL (1995) The spinal loop dialysis catheter: characterization of use in the unanesthetized rat. J Neurosci Methods 62:43-53.

Martin TJ, Kim SA, Eisenach JC (2006) Clonidine maintains intrathecal self-administration in rats following spinal nerve ligation. Pain 125:257-263.

McClung CA, Sidiropoulou K, Vitaterna M, Takahashi JS, White FJ, Cooper DC, Nestler EJ. (2005) Regulation of dopaminergic transmission and cocaine reward by the Clock gene. Proc Natl Acad Sci USA 102:9377-9381.

McFarland K, Lapish CC, Kalivas PW (2003) Prefrontal glutamate release into the core of the nucleus accumbens mediates cocaine-induced reinstatement of drug-seeking behavior. J Neurosci 23:3531-3537.

Nakahara D, Nakamura M, Iigo M, Okamura H (2003) Bimodal circadian secretion of melatonin from the pineal gland in a living CBA mouse. Proc Natl Acad Sci USA 100:9584-9589.

Olsen CM, Winder DG (2006) A method for single-session cocaine self-administration in the mouse. Psychopharmacology (Berl) 187:13-21.

Olsen CM, Winder DG (2009) Operant sensation seeking engages similar neutral substrates operant drug seeking in C57 mice. Neuropsychopharmacology 34:1685-1694.

Proescholdt MG, Huttol B, Brady LS, Herkenham M (2000) Studies of cereberospinal fluid flow and penetration into brain following lateral ventricle and cisterna magna injections of the tracer $\left[{ }^{14} \mathrm{C}\right]$ insulin in rat. Neuroscience 95:577-592.

Roberts DC, Brebner K, Vincler M, Lynch WJ (2002) Patterns of cocaine self-administration in rats produced by various access conditions under a discrete trials procedure. Drug Alcohol Depend 67: 291-299.

Schndler CW, Panlilio LV, Thorndike EB (2009) Effect of rate of delivery of intravenous cocaine on self-administration in rats. Pharmac Biochem Behav 93:375-381. 
Soria G, Barbano MF, Maldonado R, Valverde O (2008) A reliable method to study cue-, priming- and stress-induced reinstatement of cocaine self-administration in mice. Psychopharmacology (Berl) 199:593-603.

Soria G, Mendizábal V, Touriño C, Robledo P, Ledent C, Parmentier M, Maldonado R, Valverde O (2005) Lack of CB1 cannabinoid receptor impairs cocaine self-administration. Neuropsychopharmacology 30:1670-1680.

Spanagel R, Pendyala G, Abarca C, Zghoul T, Sanchis-Segura C, Magnone MC, Lascorz J, Depner M, Holzberg D, Soyka M, Schreiber S, Matsuda F, Lathrop M, Schumann G, Albrecht U (2005) The clock gene Per2 influences the glutamatergic system and modulates alcohol consumption. Nat Med $11: 35-42$.

Spanagel R, Sanchis-Segura C (2003) The use of transgenic mice to study addictive behaviour. Clin Neurosci Res 3:325-331.

Thomsen M, Caine SB (2007) Intravenous drug self-administration in mice: practical considerations. Behav Genet 37:101-118.

Waga J, Ehinger B (1995) Passage of drugs through different intraocular microdialysis membranes. Graefes Arch Clin Exp Ophthalmol 233:31-37.

Yan Y, Yamada K, Nitta A, Nabeshima T. (2006) Relapse of methamphetamine-seeking behavior in $\mathrm{C} 57 \mathrm{BL} / 6 \mathrm{~J}$ mice demonstrated by a reinstatement procedure involving intravenous self-administration. Behav Brain Res 168:137-143

Yan Y, Yamada K, Niwa M, Nagai T, Nitta A, Nabeshima T. (2007) Enduring vulnerability to reinstatement of methamphetamine-seeking behavior in glial-cell-line-deprived neurotrophic factor mutant mice. FASEB J 21:1994-2004.

Zhang XM, Ohishi K, Hiramitsu T (2001) Microdialysis measurement of ascorbic acid in rabbit vitreous after photodynamic reaction. Exp Eye Res 73:303-309.

Zhang Y, Svenningsson P, Picetti R, Schlussman SD, Nairn AC, Ho A, Greengard P, Kreek MJ (2006) Cocaine self-administration in mice is inversely related to phosphorylation at $\mathrm{Thr} 34$ (protein kinase A site) and Ser130 (kinase CK1 site) of DARPP-32. J Neurosci 26:2645-2651. 


\section{Figure legends}

Fig. 1. a: CT images of a mouse with the probe chronically implanted into the superior cistern, in which the coronal, sagital, and horizontal planes are shown. A CT image of the probe was taken after injection of contrast material. The distance from the bregma is given in millimeters on the slice for each orientation, in which the coronal slice is anterior to the bregma, the sagital slice is to the left of bregma, and the horizontal slice is to ventral to bregma. b: The bottom schematic diagram indicating the arrangement of the probe in the superior cistern and the placement of inlet and outlet teflon tubes, a hook and a plastic protector. The red crosshair shows the position of the slices.

Fig. 2. Operant chamber for drug self-administration in mice. (a): Pump for delivery of drug, (b): pump for delivery of Ringer solution, (c): swivel on balance arm, (d): sample tube for collecting perfusate, (e): infrared sensor for measuring locomotor activity, (f): holes for nose-poking with or without discriminative light and tone cues, (g) food pellets and (h) water bottle.

Fig. 3. Number of nose-pokes on active or inactive holes during the last 3 days of the training from Experiment 1. Data are mean \pm SEM $* * * p<0.001$ versus inactive nose-pokes for each day.

Fig. 4. a: Self-administration raw data for a representative subject allowed continuous, unlimited access to cocaine at each of five unit doses. The time of day is indicated horizontally, and consecutive days are indicated vertically. Each horizontal line is $24 \mathrm{~h}$ and consists of 96 consecutive 15-min bins plotted from left to right. The dark period is indicated by a shaded bar along the abscissa. b: Dose-effect curve for cocaine self-administration. A significant effect of dose was revealed $(F(4,16)=3.10, p=0.0457)$ and post-hoc analysis showed a significant difference between doses of 6 and 48 $\mu \mathrm{g} /$ infusion $\left({ }^{*} p<0.05\right)$. $\mathrm{c}$ : Dose-related increase in overall cocaine intake. The repeated measure ANOVA revealed a significant effect of dose $(F(4,16)=25.64, p<0.0001)$ and post-hoc analysis showed significant differences between doses of 12, 24, 48 $\mu \mathrm{g} /$ infusion with respect to $3 \mu \mathrm{g}$ /infusion $(\# p<0.05$, \#\#\#p<0.001). d: Dose-effect curve 
for locomotor activity. The repeated measure ANOVA revealed significant effect of dose $(F(4,16)=6.13, p=0.0034)$ and post-hoc analysis showed significant differences between doses of 12, 24, $48 \mu \mathrm{g}$ /infusion versus $3 \mu \mathrm{g} /$ infusion $(\dagger \mathrm{p}<0.05$, $\dagger \dagger \dagger \mathrm{p}<0001)$. The animals were allowed to self-administer cocaine at each unit dose during three consecutive daily 24-h sessions. Data are expressed as mean \pm SEM, averaged across the three sessions. The average of nose-poke responses or activity counts across last 3 days of extinction was served as the baseline condition (B).

Fig. 5. a: The number of nose-pokes in the active and inactive holes on each of the 10 daily extinction sessions. Histogram in the inset shows the comparison of nose-poke responses on the first and last 3 days. Data are represented as mean \pm SEM. ${ }^{*} p<0.05$ different from inactive hole responses $\# p<0.05$ different from the first 3 daily sessions for the number of active hole responses. $b$ and $c$ : Cocaine priming. The number of nose-pokes on the previously active and inactive holes (b) and activity counts (c) during the 3-h test of reinstatement following priming infusions of Ringer (baseline) or intrathecal cocaine (48 $\mu \mathrm{g}$ /infusion). Data are represented as mean \pm SEM. ${ }^{*} p<0.05$ different from inactive hole responses. $\# p<0.05$ different from the baseline condition for the number of active hole responses. $\dagger p<0.05$ different from the baseline condition for locomotor activity.

Fig. 6. a: The number of nose-pokes in the active and inactive holes in the Ringer self-administration group on each of the 20 daily self-administration sessions. b: The number of cocaine infusions (reinforcers obtained) and of nose-pokes in the active and inactive holes in the cocaine self-administration group on each of the 20 daily self-administration sessions. The repeated measure ANOVA revealed significant main effects of hole $(F(1,4)=25.50, p=0.0072)$ and session $(F(19,76)=2.05, p=0.0148)$ and also a hole by session interaction $(F(19,76)=3.85, p<0.001)$. c: The total number of active nose-pokes under an FR1 schedule during sessions 6-10 and under an FR2 schedule during sessions 16-20. Data are represented as mean \pm SEM. $* p<0.05$; ${ }^{* *} p<0.01 ; * * * p<0.01$ different from corresponding inactive nose pokes, $\# p<0.05$ different from the FR1 condition.

Fig. 7. Double plotted, daily patterns of cocaine self-administration and associated 
locomotor activity. a: A representative "control" pattern of Ringer self-administration from an animal. b: A representative "no-binge" pattern of cocaine self-administration from an animal. c: Two representative "binge-like" patterns of cocaine self-administration from two separate animals. The binge was defined as a series of infusions with periods of cocaine abstinence no longer than $3 \mathrm{~h}$ for over a day. The time of day is indicated horizontally, and consecutive days are indicated vertically. The horizontal open bar at the top of each panel shows the light period, and the filled bar shows the dark period. Data of 96 consecutive 15-min bins per day are graphed as color diagrams.

Fig. 8. Cocaine cues. The number of nose-pokes in the active and inactive holes (a) and activity counts (b) during a 3-h test for cocaine seeking in the presence of a tone-light compound cue previously paired with cocaine injections. Data are represented as mean \pm SEM. ${ }^{*} p<0.05$ different from the vehicle control group for the number of active nose pokes. $\# p<0.05$ different from inactive nose pokes. 
a
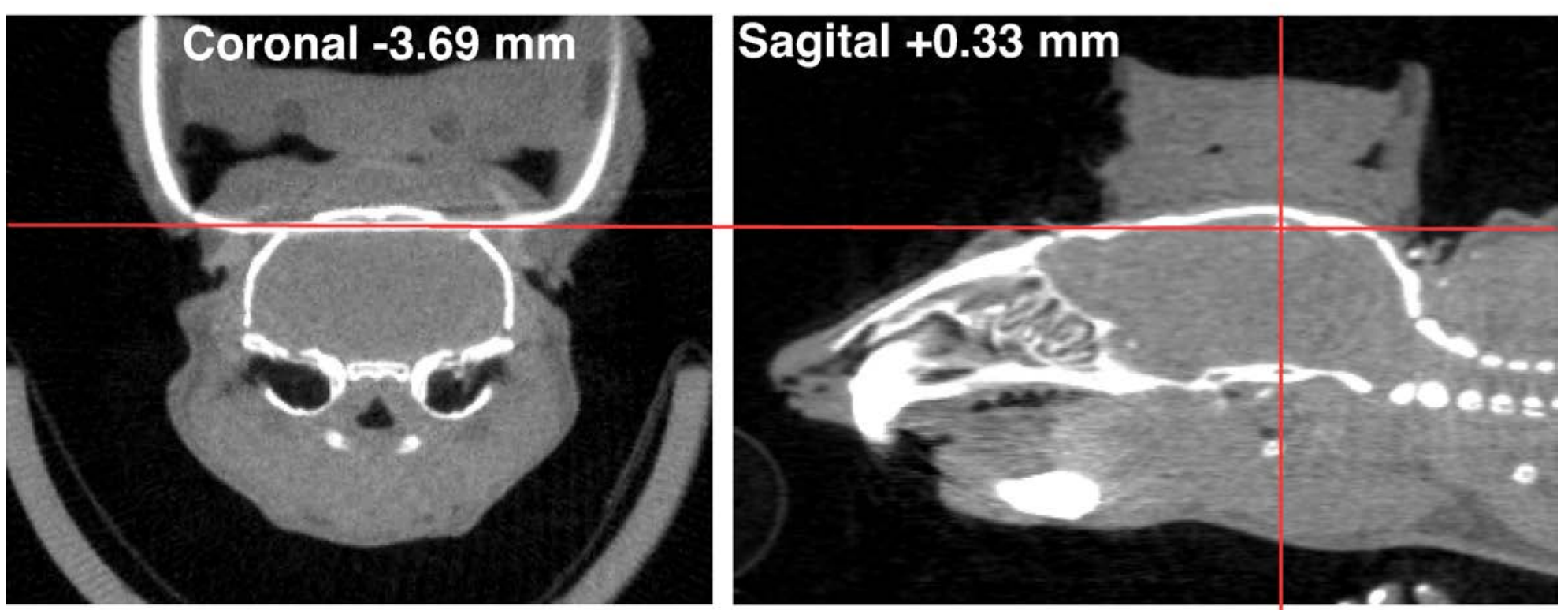

b

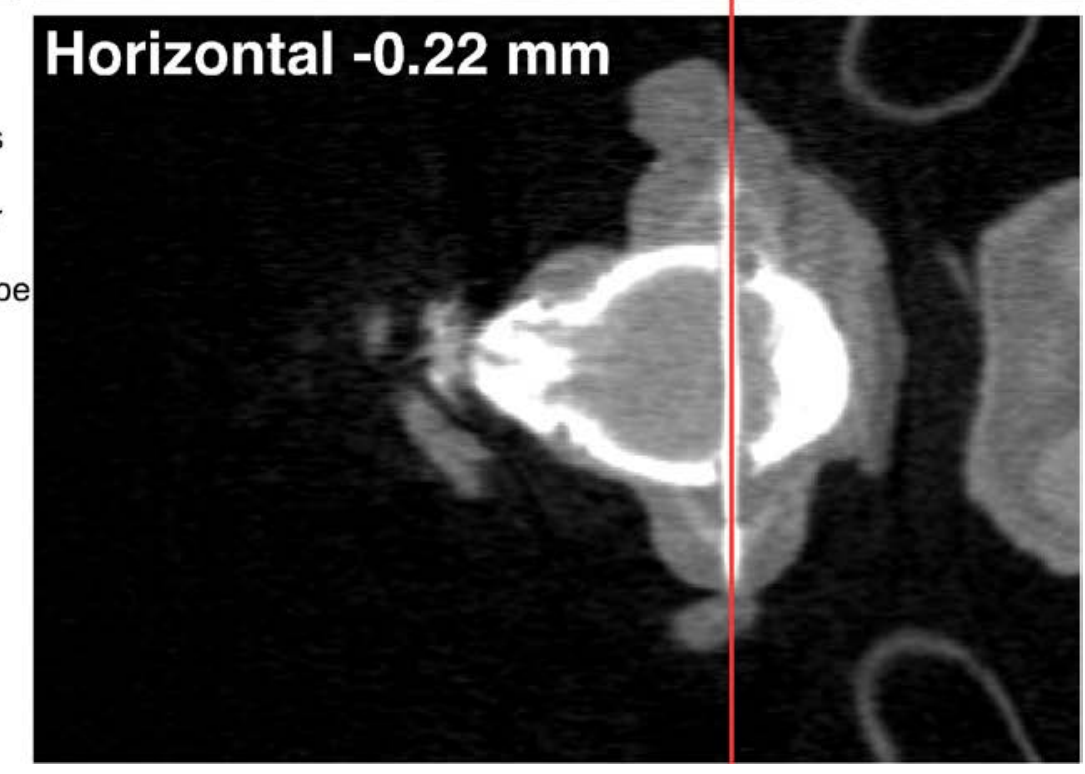


(a)

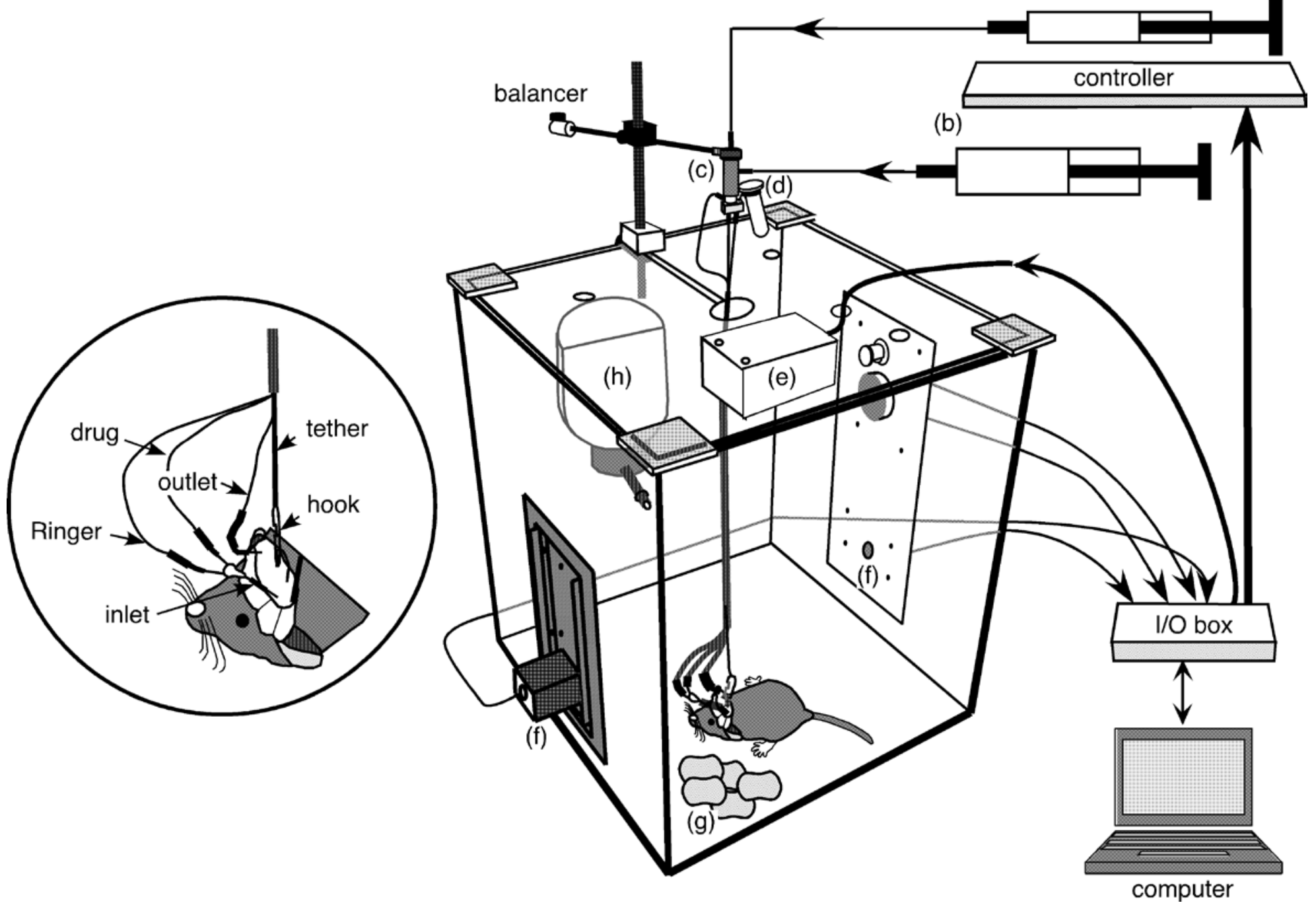




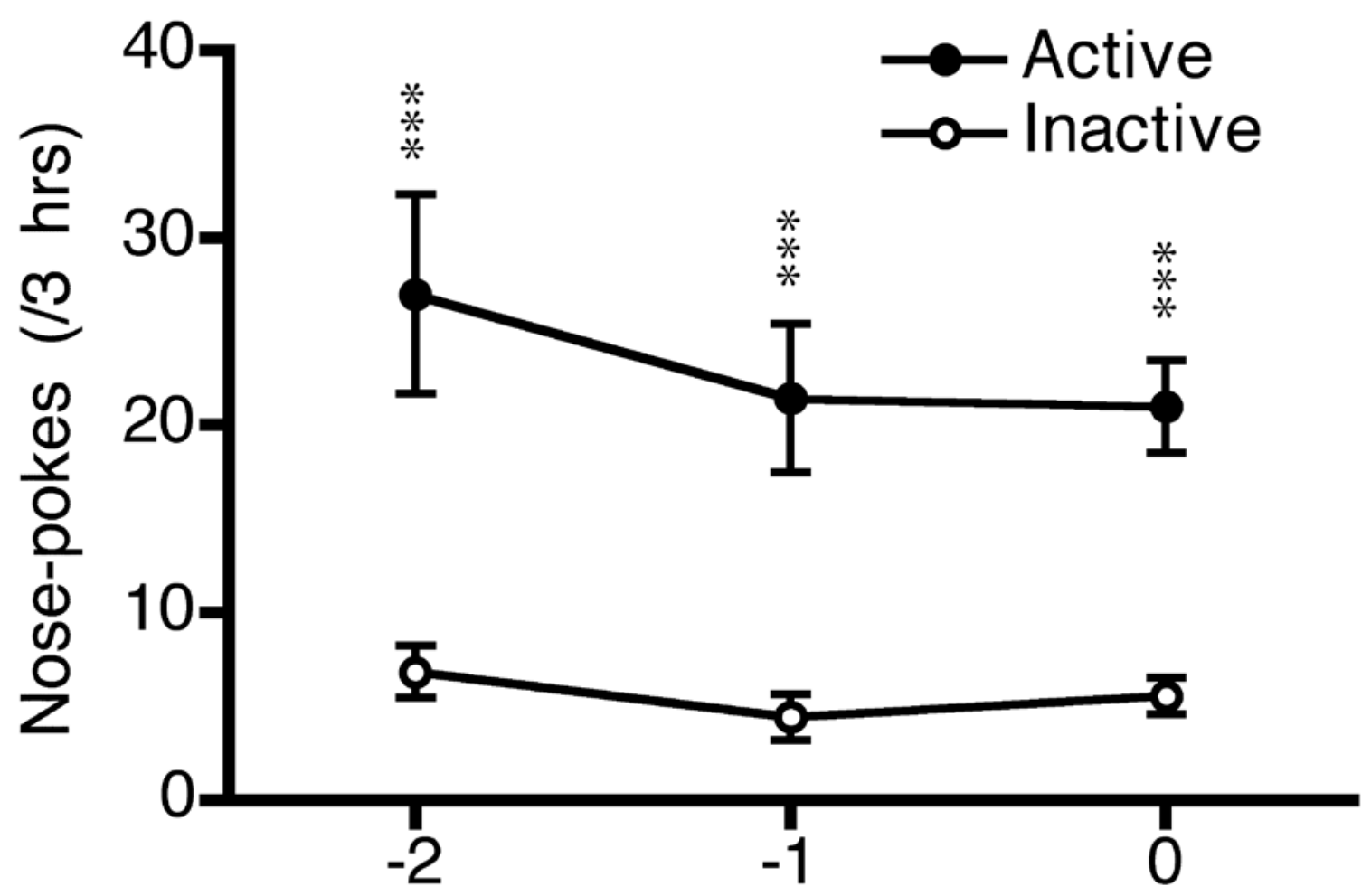

Days before reaching criterion 
a

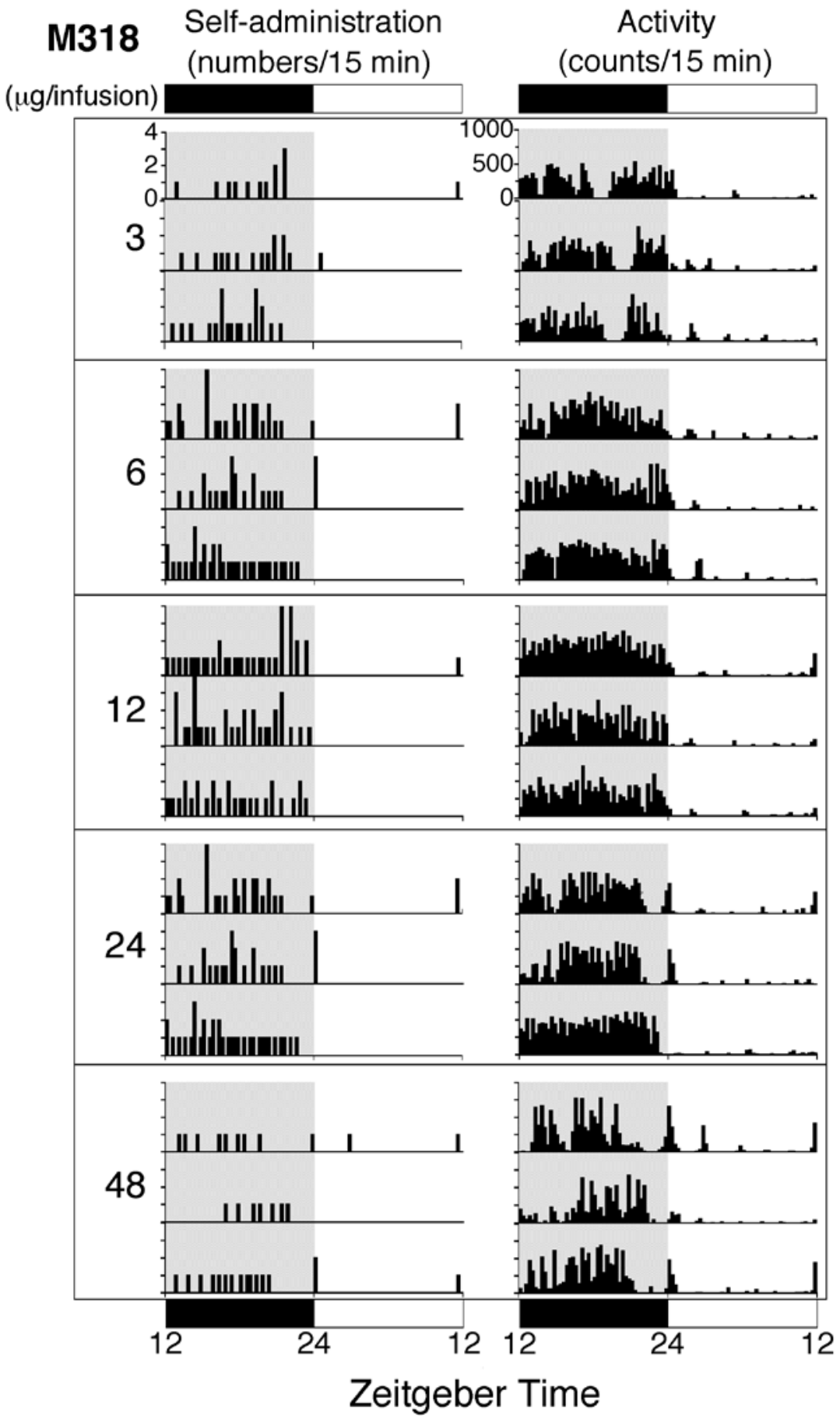

b

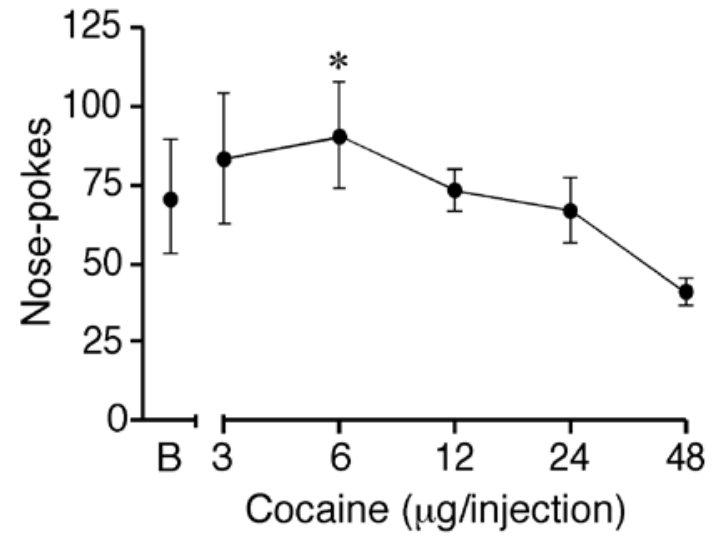

C

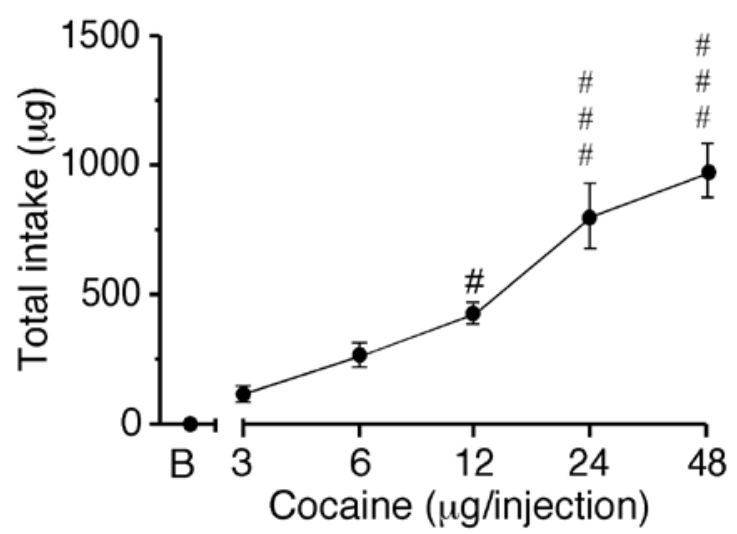

d

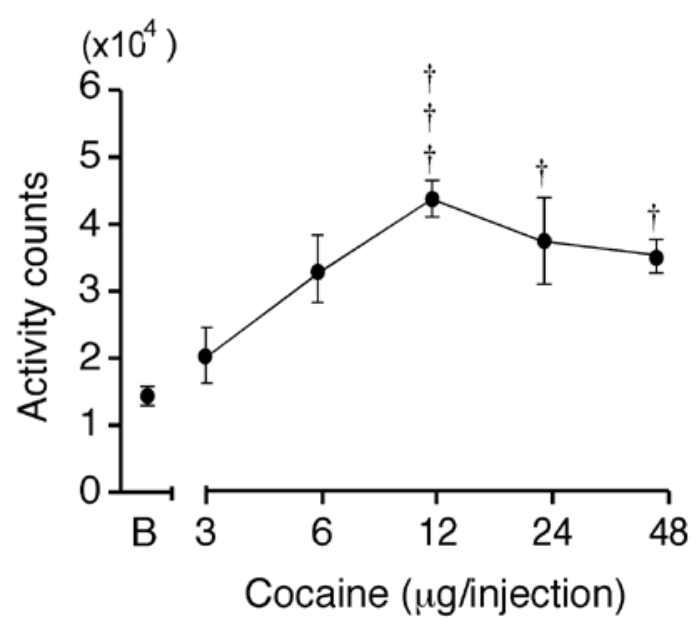



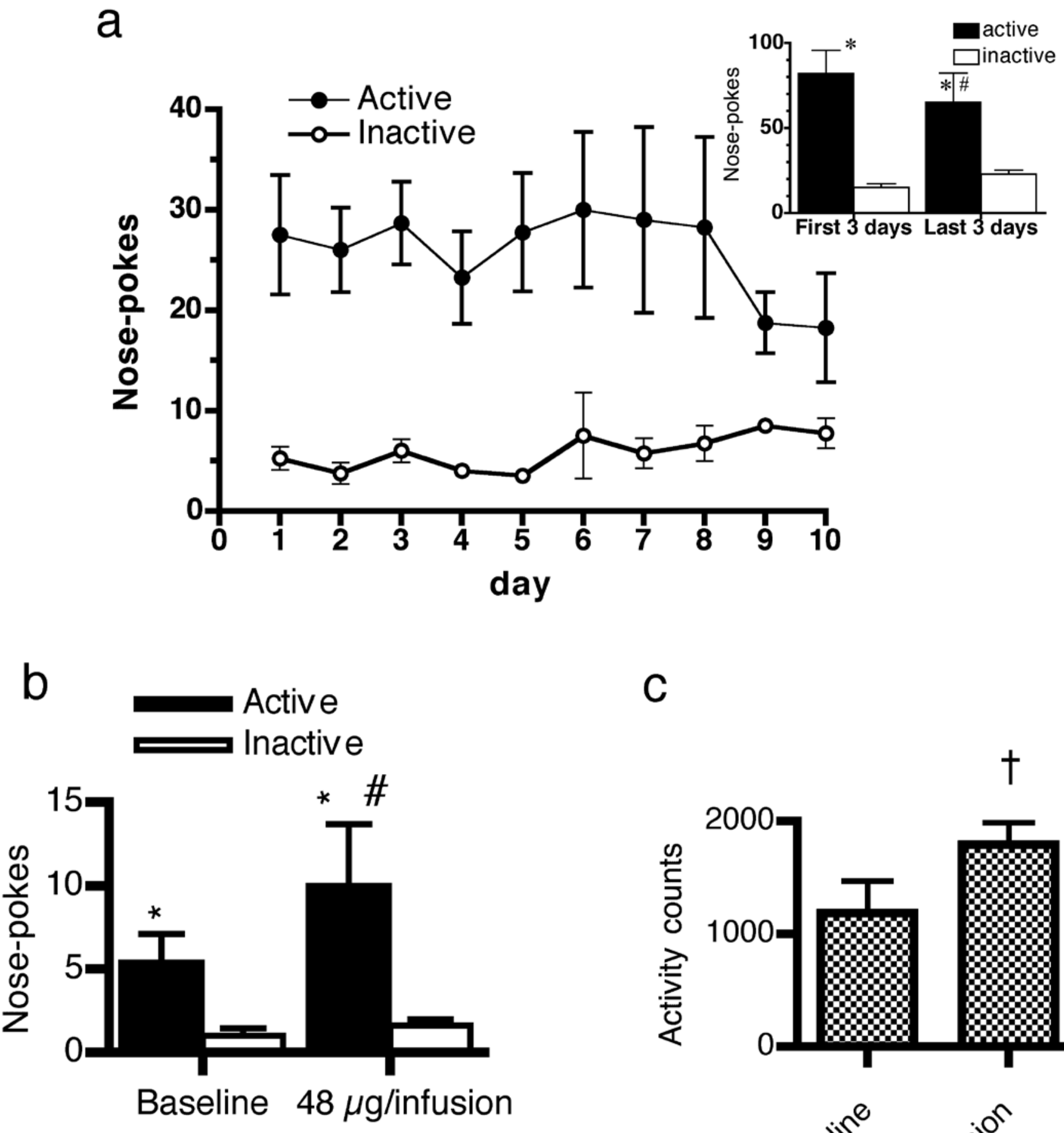

C

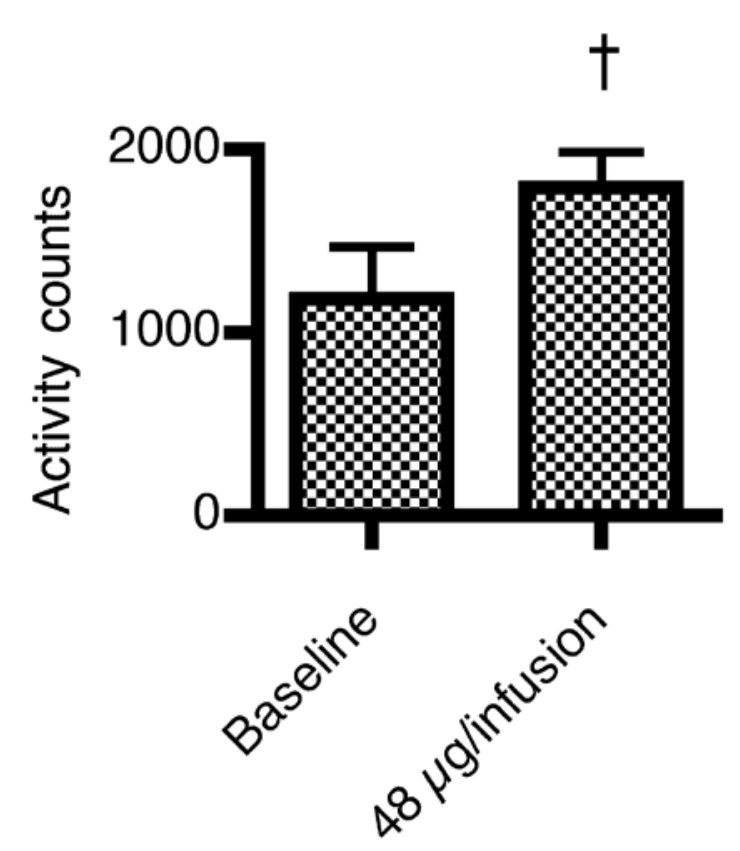



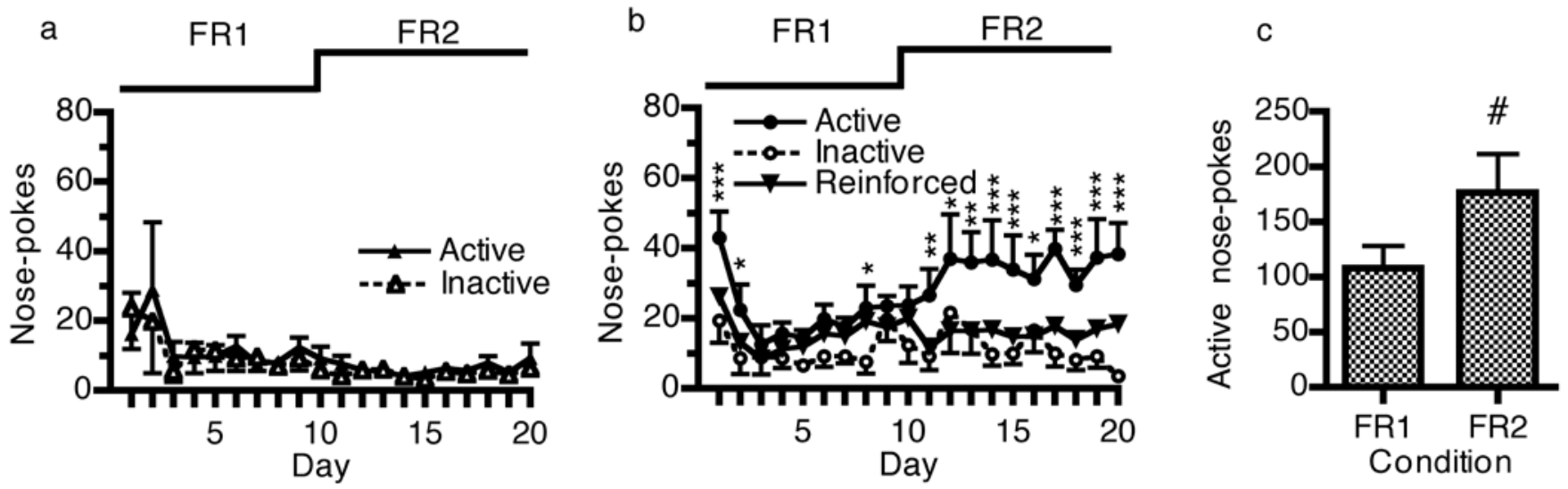
Self-administration
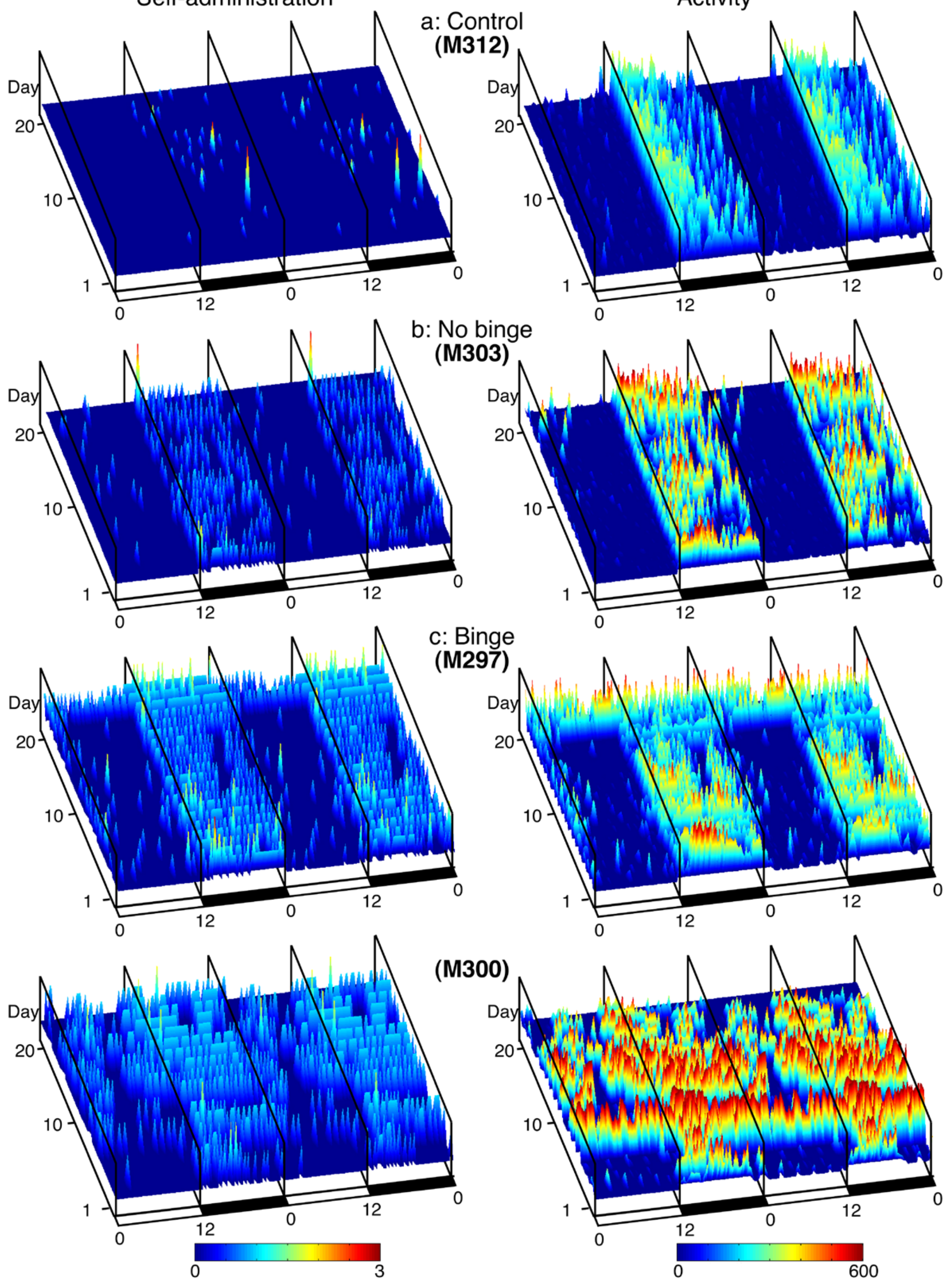


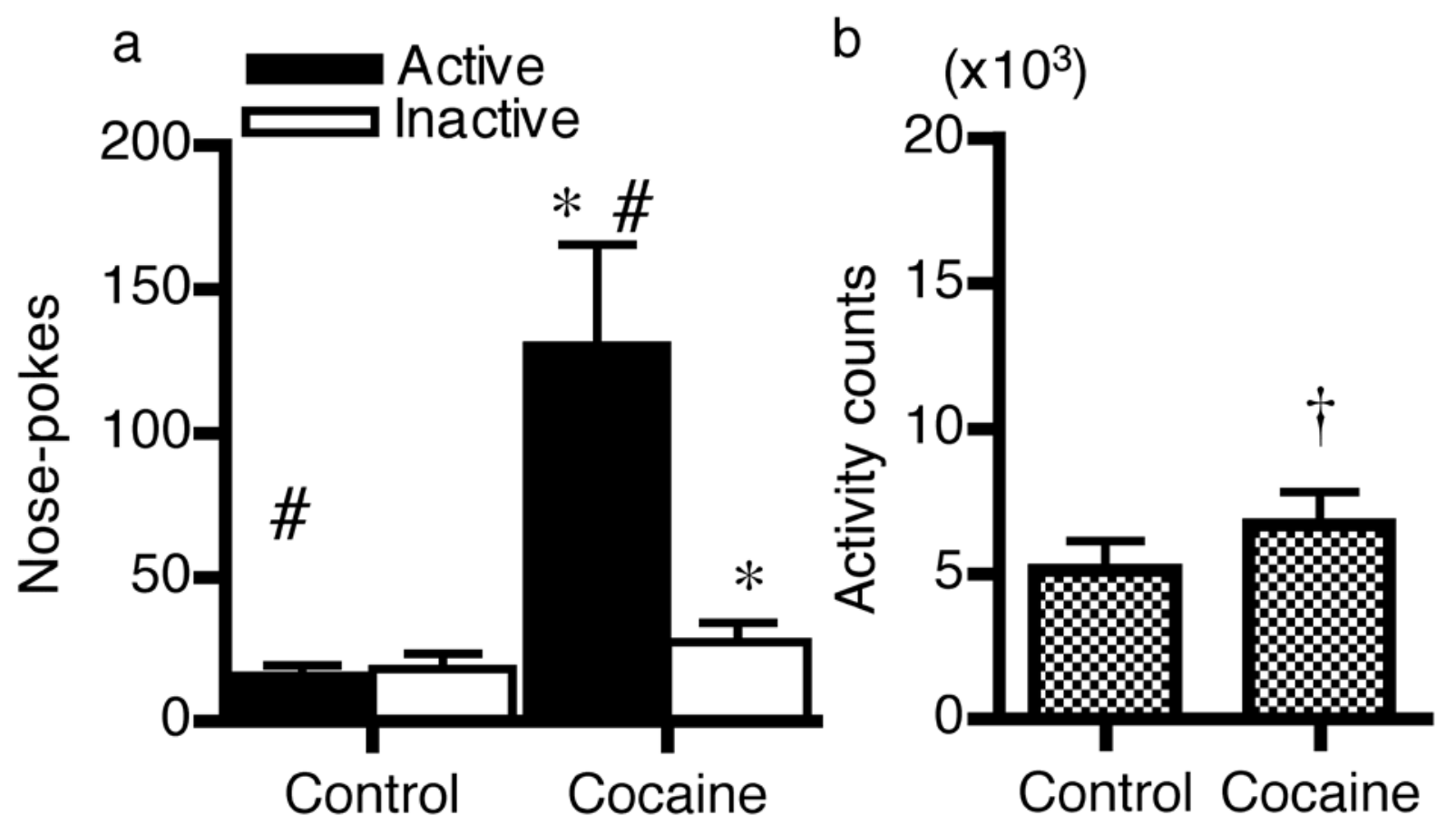

